\title{
Rendimento de tubérculos de clones elite de batata
}

\section{Giovani O Silva ${ }^{1}$; Arione S Pereira ${ }^{2}$; Fabio A Suinaga ${ }^{3}$; Agnaldo DF Carvalho ${ }^{3}$}

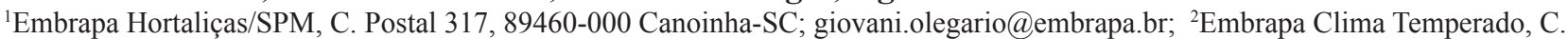
Postal 403, 96001-970 Pelotas-RS; arione.pereira@embrapa.br; ${ }^{3}$ Embrapa Hortaliças, C. Postal 218 70351-970 Brasilia-DF; fabio. suinaga@embrapa.br; agnaldo.carvalho@embrapa.br

\section{RESUMO}

O objetivo do presente trabalho foi verificar o desempenho de sete clones elite de batata quanto a caracteres de rendimento de tubérculos, em comparação com cultivares utilizadas em grande escala no Brasil. O experimento foi conduzido no campo experimental da Embrapa Produtos e Mercado, Canoinhas-SC. Foram avaliados sete clones elite desenvolvidos pelo Programa de Melhoramento Genético de Batata da Embrapa e duas cultivares comerciais (Agata e Asterix), no cultivo de primavera de 2012. O delineamento experimental foi em blocos casualizados com quatro repetições e parcelas compostas de uma linha com 10 plantas. Aos 110 dias após o plantio foram realizadas a colheita e avaliações de caracteres componentes do rendimento de tubérculos. Os dados foram submetidos à análise de variância, agrupamento de médias por Scott \& Knott e correlações fenotípicas. Com exceção de F22-08-01, todos os clones superaram as testemunhas quanto a caracteres de rendimento, com destaque para os clones F74-08-09 e F17-08-01. O rendimento total de tubérculos foi determinado principalmente pela massa média de tubérculos e pouco influenciado pelo número total de tubérculos por planta, enquanto a massa de tubérculos comerciais foi determinada pelo número de tubérculos comerciais e massa média de tubérculos.

Palavras-chave: Solanun tuberosum, massa de tubérculos, clones avançados.

\begin{abstract}
Tuber yield of elite potato clones

The aim of this work was to verify the performance of seven advanced potato clones in relation to yield components, compared to varieties grown in large scale in Brazil. The experiment was carried out in the experimental field of Embrapa Produtos e Mercado, Canoinhas, Santa Catarina state, Brazil. Seven advanced potato clones developed in Embrapa Potato Breeding Program, and two commercial cultivars (Agata and Asterix) were evaluated in the spring season of 2012. A randomized complete block design with four replications of 10 plants per plot was used. Plants of each plot were harvested 110 days after planting, and evaluated for yield components. The data were submitted to analysis of variance, grouping means by the Scott \& Knott test and phenotypic correlation. Except F22-08-01, all clones exceeded the control cultivars for yield trait components, mainly the clones F74-08-09 and F17-08-01. The total tuber yield was mainly determined by the average tuber mass and little influenced by the total number of tubers per plant, while marketable tuber mass was similarly determined by the marketable tuber number and average tuber weight.
\end{abstract}

Keywords: Solanun tuberosum, tuber mass, advanced clones.

\section{(Recebido para publicação em 3 de julho de 2013; aceito em 25 de março de 2014) (Received on July 3, 2013; accepted on March 25, 2014)}

A maioria das cultivares de batata utilizadas no Brasil é de origem européia e sofre os efeitos adversos das temperaturas mais elevadas (Menezes et al., 2001) e do fotoperíodo mais curto, ocasionando redução do ciclo vegetativo e do potencial produtivo (Kooman \& Rabbinge, 1996), além de maior pressão de alguns patógenos e pragas (Pinto et al., 2010). Para minimizar a ação desses efeitos, é utilizada uma elevada quantidade de insumos visando a obtenção de uma produtividade razoável, reduzindo a sustentabilidade da cultura.

A obtenção de cultivares nacionais adaptadas às condições de cultivo das regiões brasileiras e resistentes às principais doenças que incidem sobre a batateira é a alternativa mais viável para aumentar a produtividade da cultura e a rentabilidade para o produtor (Gadum et al., 2003). O grande desafio dos melhoristas de batata consiste em disponibilizar permanentemente cultivares que atendam às exigências dos consumidores, que cada vez mais priorizam produtos de qualidade (visuais e culinárias), dos produtores (maior rendimento aliado à precocidade) e das indústrias (qualidade de fritura) (Silva et al., 2012). Portanto, estudos que permitam o melhor conhecimento da expressão destes caracteres frente às condições ambientais e a verificação da potencialidade de clones para se tornarem cultivares, são importantes.

Quanto aos componentes de rendimento de tubérculos, sabe-se que plantas que apresentam elevado número de tubérculos apresentam, geralmente, tubérculos menores (Silva et al., 2012). Tanto o número quanto o tamanho dos tubérculos influenciam diretamente o rendimento de tubérculos comerciais
(Silva et al., 2006). Desta forma, é importante no processo de seleção, encontrar o equilíbrio entre número e tamanho de tubérculos.

O objetivo do presente trabalho foi verificar o desempenho de sete clones elite de batata quanto a caracteres relacionados ao rendimento de tubérculos, em comparação com cultivares utilizadas em grande escala no País.

\section{MATERIAL E MÉTODOS}

O experimento foi realizado no campo experimental da Embrapa Produtos e Mercado, Canoinhas-SC (26¹0'38'S, $50^{\circ} 23^{\prime} 24^{\prime \prime} \mathrm{O}, 839 \mathrm{~m}$ de altitude), na primavera de 2012. Foram avaliados sete clones elite pertencentes ao programa de melhoramento genético da Embrapa (C2519-12-06, F74-08-09, F22-08-01, 
F17-08-01, F82-08-10, F37-08-01, F50-08-01), em comparação com as cultivares testemunha Agata e Asterix.

$\mathrm{O}$ delineamento experimental foi em blocos casualizados com quatro repetições, sendo cada parcela composta de uma linha de quatro metros com 10 plantas. Foram utilizados tubérculos-semente do tipo II com quatro meses de armazenamento em câmara fria sob temperaturas variando de 3,5 a $4,5^{\circ} \mathrm{C}$, plantados espaçados em $0,75 \mathrm{~m}$ entre linhas e 0,40 m dentro da linha, no dia 17 de agosto de 2012. Como fertilizante foi utilizada a fórmula comercial 5-30-10 de N-P-K, respectivamente, na dosagem de $2 \mathrm{t} \mathrm{ha}^{-1}$. Os tratos culturais e fitossanitários seguiram as recomendações da região (Pereira, 2010). Após a senescência das plantas, aos 110 dias após o plantio, foi realizada a colheita.

Todos os tubérculos plantados brotaram. Foram avaliados os caracteres número de tubérculos comerciais/ parcela, com diâmetro acima de $45 \mathrm{~mm}$ (NTC); número total de tubérculos/ parcela (NTT); massa de tubérculos comerciais (MTC), em kg/parcela; massa total de tubérculos (MTT), em $\mathrm{kg}$ /parcela; percentagem de tubérculos comerciais (\%TC), obtida pela divisão do número de tubérculos comerciais e o número total de tubérculos, multiplicado por 100; e, massa média de tubérculos (MMT) em g/tubérculo, obtida pela divisão da massa total e o número total de tubérculos.

Os dados de cada caráter avaliado foram verificados quanto à distribuição normal dos erros por meio do teste de Lilliefors, submetidos à análise de variância, agrupamento de médias pelo teste de Scott \& Knott, correlação fenotípica, com a utilização do programa GENES (Cruz, 2006).

Estimaram-se os coeficientes de variação experimental (CVe) e genético (CVg), em percentagem da média geral, respectivamente, por meio das expressões

$$
\begin{aligned}
& \mathrm{CVe}=100 \cdot \sqrt{Q M e / m e ́ d i a} \text { e } \\
& \mathrm{CVg}=100 \cdot \sqrt{\hat{\sigma}_{g} / \text { média }}(\mathrm{Cruz},
\end{aligned}
$$
2006).

\section{RESULTADOS E DISCUSSÃO}

Todos os caracteres avaliados apre- sentaram distribuição normal dos erros. A análise de variância revelou diferenças significativas $(\mathrm{p}<0,05)$ entre os genótipos para todos os caracteres. Os coeficientes de variação variaram de $12,70 \%$ para massa média de tubérculos (MMT) a 22,76\% para massa de tubérculos comerciais (MTC) (Tabela 1). Estes valores são semelhantes aos obtidos por Silva et al. (2006), que variaram de 17,31 a $21,03 \%$ para os caracteres rendimento (MTT), número cientes foram semelhantes também aos verificados por Bisognin et al. (2008), com valores variando entre 16,19 e tubérculos de clones de batata com diferentes tamanhos. Da mesma forma, Costa et al. (2007) verificaram valores entre 22,70 e $18,30 \%$, para massa total de tubérculos e número total de tubérculos, respectivamente.

A relação entre o coeficiente de variação genética e o coeficiente de variação ambiental $(\mathrm{CVg} / \mathrm{CV})$ foi supede tubérculos (NTT) e MMT. Os coefi$25,60 \%$, para o caráter rendimento de

rior à unidade para todos os caracteres, com exceção do número de tubérculos comerciais (NTC) $(0,93)$, indicando que a variação de ordem genética superou a ambiental para a maioria dos caracteres e que a seleção baseada nestes caracteres seria eficiente. Considerando que o rendimento de tubérculos de batata é um caráter quantitativo, que normalmente sofre grande influência ambiental (Silva et al., 2006), conclui-se que este experimento teve adequada precisão experimental. A superioridade do valor do $\mathrm{CVg}$ para caracteres relacionados ao rendimento de tubérculos de batata também foi verificada por Silva et al. (2012), enquanto Neder et al. (2010) verificaram, na média de quatro experimentos, CV de 38,50\% e CVg 27,16\%, e, para produção de tubérculos por planta, Simon et al. (2009) verificaram valores da relação $\mathrm{CVg} / \mathrm{CV}$ variando de 0,72 a 0,82 .

Quanto ao NTT, a testemunha 'Asterix' apresentou o maior valor, indicando grande potencial produtivo; enquanto

Tabela 1. Médias, coeficientes de variação fenotípica (CV), relação entre coeficiente de variação genotípica e ambiental $(\mathrm{CVg} / \mathrm{CV})$ e média geral, para caracteres componentes de rendimento de sete clones e duas cultivares de batata avaliados em 2012 [means, phenotypic coefficient of variation, relation between genotypic and phenotypic coefficient of variation $(\mathrm{CVg} / \mathrm{CV})$ and general mean, for yield components of seven potato clones and two cultivars

\begin{tabular}{|c|c|c|c|c|c|c|}
\hline Clone & NTT $^{2}$ & MTT & NTC & MTC & TC (\%) & MMT \\
\hline Asterix & $188,25 \mathrm{a}^{1}$ & $13,75 \mathrm{a}$ & $25,00 \mathrm{~b}$ & $5,25 \mathrm{c}$ & $13,45 \mathrm{c}$ & $73,33 \mathrm{~d}$ \\
\hline F22-08-01 & $132,50 \mathrm{~b}$ & $8,87 \mathrm{~b}$ & $28,25 \mathrm{~b}$ & $4,00 \mathrm{~d}$ & $21,86 \mathrm{c}$ & $66,93 \mathrm{~d}$ \\
\hline F82-08-10 & $124,50 \mathrm{~b}$ & $11,25 \mathrm{~b}$ & $37,75 \mathrm{a}$ & $6,00 \mathrm{c}$ & $30,44 \mathrm{~b}$ & $90,30 \mathrm{c}$ \\
\hline Agata & $124,00 \mathrm{~b}$ & $8,82 \mathrm{~b}$ & $22,75 \mathrm{~b}$ & $2,95 \mathrm{~d}$ & $18,44 \mathrm{c}$ & $71,59 \mathrm{~d}$ \\
\hline F50-08-01 & $120,75 \mathrm{~b}$ & $11,75 \mathrm{a}$ & $38,25 \mathrm{a}$ & $7,00 \mathrm{c}$ & $31,95 \mathrm{~b}$ & $97,82 \mathrm{c}$ \\
\hline C2519-12-06 & $115,25 \mathrm{~b}$ & $10,75 \mathrm{~b}$ & $35,25 \mathrm{a}^{1}$ & $6,25 \mathrm{c}$ & $30,05 \mathrm{~b}$ & $92,97 \mathrm{c}$ \\
\hline F17- & $100,75 \mathrm{c}$ & $12,25 \mathrm{a}$ & & $8,50 \mathrm{~b}$ & $41,82 \mathrm{a}$ & $122,77 \mathrm{~b}$ \\
\hline F37-08-01 & $99,75 \mathrm{c}$ & $9,75 \mathrm{~b}$ & $36,00 \mathrm{a}$ & $5,87 \mathrm{c}$ & $36,01 \mathrm{~b}$ & $98,67 \mathrm{c}$ \\
\hline F74-08-09 & $91,25 \mathrm{c}$ & $14,12 \mathrm{a}$ & $44,25 \mathrm{a}$ & $10,87 \mathrm{a}$ & $48,63 \mathrm{a}$ & $155,56 \mathrm{a}$ \\
\hline CV (\%) & 13,99 & 14,64 & 20,37 & 22,76 & 20,16 & 12,70 \\
\hline $\mathrm{CVg} / \mathrm{CV}$ & 1,58 & 1,06 & 0,93 & 1,56 & 1,76 & 2,22 \\
\hline Média & 121,88 & 11,25 & 34,33 & 6,30 & 30,29 & 96,66 \\
\hline
\end{tabular}
grown in 2012]. Canoinhas, Embrapa Produtos e Mercado, 2013.

${ }^{1}$ Médias seguidas pela mesma letra, em cada coluna, pertencem ao mesmo grupo pelo teste de Scott-Knott em nível de $5 \%$ de probabilidade de erro. ${ }^{2} \mathrm{NTT}=$ número total de tubérculos por parcela; $\mathrm{MTT}=$ massa total de tubérculos em $\mathrm{kg}_{\text {parcela }}{ }^{-1} ; \mathrm{NTC}=$ número de tubérculos comerciais por parcela; $\mathrm{MTC}=$ massa de tubérculos comerciais em $\mathrm{kg}_{\text {parcela }}{ }^{-1} ; \mathrm{TC}=$ porcentagem de tubérculos comerciais; MMT= massa média de tubérculo em $\mathrm{g}$ tubérculo ${ }^{-1}$ ( ${ }^{1}$ means followed by the same letter, in each column, do not differ significantly among themselves by the Scott-Knott test at $5 \%$ of probability of error. ${ }^{2} \mathrm{NTT}=$ total tuber number per plot; $\mathrm{MTT}=$ total tuber yield in $\mathrm{kg} \mathrm{plot}^{-1} ; \mathrm{NTC}=$ number of marketable tubers per plot; $\mathrm{MTC}=$ marketable tuber yield in $\mathrm{kg} \mathrm{plot}^{-1} ; \mathrm{TC}=$ percentage of marketable tubers; MMT= average tuber weight in $\mathrm{g} \mathrm{tuber}^{-1}$ ). 
Tabela 2. Correlações fenotípicas entre caracteres componentes de rendimento de tubérculos de batata (phenotypic correlations among potato tuber yield components). Canoinhas, Embrapa Produtos e Mercado, 2013.

\begin{tabular}{lccclc}
\hline & MTT & NTC & MTC & \%TC & MMT \\
\hline NTT $^{1}$ & 0,06 & $-0,91^{*}$ & $-0,62^{*}$ & $-0,91^{*}$ & $-0,70^{*}$ \\
MTT & & 0,43 & $0,74^{*}$ & 0,38 & $0,65^{*}$ \\
NTC & & & $0,92^{*}$ & $0,99^{*}$ & $0,97^{*}$ \\
MTC & & & & $0,90^{*}$ & $0,99^{*}$ \\
\%TC & & & & & $0,95^{*}$ \\
\hline
\end{tabular}

${ }^{1} \mathrm{NTT}=$ número total de tubérculos por parcela; $\mathrm{MTT}=$ massa total de tubérculos; $\mathrm{NTC}=$ número de tubérculos comerciais; $\mathrm{MTC}=$ massa de tubérculos comerciais; $\mathrm{TC}=$ porcentagem de tubérculos comerciais; MMT $=$ massa média de tubérculo, ${ }^{*}$ Significativo a $5 \%$ pelo teste $\mathrm{t}(\mathrm{NTT}=$ total tuber number; $\mathrm{MTT}=$ total tuber yield; $\mathrm{NTC}=$ number of marketable tubers; $\mathrm{MTC}=$ marketable tuber yield; $\mathrm{TC}=$ percentage of marketable tubers; $\mathrm{MMT}=$ average tuber weight; *Significant at $5 \%$ of probability by the $t$ test).

os clones C2519-12-06, F22-08-01, F82-08-10 e F50-08-01, e 'Agata' constituíram o segundo grupo com maior número de tubérculos. Os demais clones classificaram-se no grupo inferior.

Em relação à massa total de tubérculos (MTT), houve a formação de dois grupos, sendo que os genótipos com maior produção foram F74-08-09, F17-08-01, F50-08-01 e a testemunha 'Asterix'.

Não foi verificada coincidência entre os clones com maior NTT e MTT, com exceção da cultivar testemunha Asterix, indicando que o rendimento total de tubérculos não foi muito influenciado pelo número de tubérculos produzidos, mas provavelmente pelo tamanho dos tubérculos. Os valores da correlação fenotípica (Tabela 2) confirmam estes resultados, pois MTT correlacionou-se fortemente $(r>0,60)$ com MTC e MMT, e o coeficiente de correlação com NTT não foi significativo. Estas correlações podem ser explicadas pelas fortes associações negativas de NTT com todos os caracteres relacionados à MTC e também com MMT; indicando que quanto maior o número de tubérculos menor o tamanho médio dos mesmos; esta conclusão é corroborada pela literatura (Gaur \& Kishore, 1978; Maris, 1988; Rodrigues \& Pereira, 2003; Silva et al., 2007). No entanto, no estudo de Rodrigues \& Pereira (2003), foi verificada maior influência do número de tubérculos do que da MMT destes no rendimento total de tubérculos de batata. Naquele trabalho não foi possível visualizar as médias dos caracteres, mas uma possibilidade para aqueles resultados seria a obtenção de menor número de tubérculos por planta.

Todos os clones agruparam-se com o maior NTC, com exceção do F22-08-01, que formou o grupo inferior junto com as duas cultivares testemunhas.

Em relação ao caráter MTC, o clone F74-08-09 destacou-se, formando isoladamente o grupo superior, seguido pelo grupo do clone F17-08-01, grupo dos clones F50-08-01, C2519-12-06, F82-08-10, F37-08-01, F50-08-01 e a cultivar Asterix. O clone F22-08-01 e a cultivar Agata formaram o grupo de mais baixa MTC.

Quanto ao caráter porcentagem de tubérculos comerciais (\%TC), os clones F74-08-09 e F17-08-01 compuseram o grupo superior, enquanto o clone F22-08-01 e as cultivares testemunhas formaram o grupo inferior. Os demais clones constituíram o grupo intermediário. A porcentagem média de tubérculos comerciais para os genótipos deste estudo foi de 30,29\%; Teixeira et al. (2010) obtiveram valor de $24,77 \%$ com o mesmo critério, tubérculos acima de $45 \mathrm{~mm}$ de diâmetro. Feltran \& Lemos (2005) obtiveram porcentagem média de tubérculos comerciais de $69,28 \%$, porém os autores consideraram como comerciais os tubérculos com diâmetro acima de $23 \mathrm{~mm}$.

No que refere-se à MMT, os genótipos agruparam-se de forma semelhante ao caráter MTC, exceto a cultivar Asterix que passou para o grupo inferior formado pelo clone F22-08-01 e a cultivar Agata.
O fato de quase todos os clones terem apresentado rendimento superior às testemunhas, que são cultivadas em larga escala no Brasil, indica que este conjunto de clones possui potencial produtivo para se tornarem cultivares.

Neste estudo a testemunha 'Asterix' foi melhor do que 'Agata' para os caracteres NTT, MTT e MTC, enquanto que para os demais caracteres ambas tiveram desempenho semelhante. Pinto et al. (2010) cultivaram estas mesmas cultivares em Minas Gerais em três locais de cultivo, compreendendo as safras das águas, de inverno e das secas, e verificaram superioridade da cv. Asterix para os caracteres porcentagem de tubérculos graúdos e MMT, enquanto que para produção total estas não apresentaram diferenças entre si. Rossi et al. (2011) realizaram um experimento no estado de São Paulo na safra de inverno em sistema orgânico e também verificaram superioridade de 'Asterix' sobre 'Agata' para os caracteres MTT, MTC e MMT. Da mesma forma, Fernandes et al. (2011), na safra de inverno no estado de São Paulo, verificaram MTT não diferentes estatisticamente para as duas cultivares, porém, 'Asterix' apresentou maior rendimento de tubérculos maiores que $45 \mathrm{~mm}$ de diâmetro. No entanto, no cultivo da primavera no estado de São Paulo, Feltran \& Lemos (2005) verificaram que estas cultivares não diferiram quanto à MTT, mas 'Agata' apresentou maior produção comercial de tubérculos. Já Silva et al. (2012) verificaram que 'Asterix' apresentou maiores \% $\%$ C e MMT e não foram verificadas diferenças significativas para MTT, NTC e MTC. Portanto, fica claro que não há superioridade absoluta quanto ao rendimento destas duas cultivares que são cultivadas em larga escala no País.

Em adição às correlações acima citadas, foram observados valores elevados entre os caracteres relacionados à MTC e MMT, conforme esperado (Tabela 2).

Desta forma, pode-se verificar que, com exceção de F22-08-01, todos os clones superaram as testemunhas quanto a caracteres de rendimento, com destaque para os clones F74-08-09 e F17-0801 . O rendimento total de tubérculos foi determinado principalmente pela MMT e pouco influenciado pelo NTT por plan- 
ta, enquanto a MTC foi determinada por ambos, NTC e MMT.

\section{AGRADECIMENTOS}

Ao CNPq pelo auxílio financeiro e ao Programa de Melhoramento Genético de Batata da Embrapa.

\section{REFERÊNCIAS}

BISOGNIN DA; MÜLLER DR; STRECK NA; ANDRIOLO JL; SAUSEN D. 2008. Desenvolvimento e rendimento de clones de batata na primavera e no outono. Pesquisa Agropecuária Brasileira 43: 699-705.

COSTA LC; BISOGNIN DA; ANDRIOLO JL; RITTER CEL; BANDINELLI MG. 2007. Identificação de clones de batata com potencial para mesa e adaptados para os cultivos de outono e primavera do Rio Grande do Sul. Ciência e Natura 29: 93-104.

CRUZ CD. 2006. Programa genes: aplicativo computacional em genética e estatística. Viçosa; UFV. 648p.

FELTRAN JC; LEMOS LB. 2005. Características agronômicas e distúrbios fisiológicos em cultivares de batata. Cientifica 33: 106-113.

FERNANDES AM; SORATTO RP; EVANGELISTA RM; SILVA BL; SOUZASCHLICK GD. 2011. Produtividade e esverdeamento pós-colheita de tubérculos de cultivares de batata produzidos na safra de inverno. Revista Ciência Agronômica 42: 502-508.

GADUM J; PINTO CABP; RIOS MCD. 2003. Desempenho agronômico e reação de clones de batata (Solanum tuberosum L.) ao PVY. Ciência e Agrotecnologia 27: 1484-1492.

GAUR PC; KISHORE H. 1978. Studies on character association in potatoes. Journal Agriculture Science 90: 215-219.

KOOMAN PL; RABBINGE R. 1996. An analysis of the relation between dry matter allocation to the tuber and earliness of a potato crop. Annals of Botany 77: 235-242.

MARIS B. 1988. Correlations within and between characters between and within generations as a measure for the early generation selection in potato breeding. Euphytica 37: 205-209.

MENEZES CB; PINTO CABP; NURMBERG PL; LAMBERT ES. 2001. Combining ability of potato genotypes for cool and warm seasons in Brazil. Crop Breeding and Applied Biotechnology 1: 145-157.

NEDER DG; PINTO CABP; MELO DS; LEPRE AL; PEIXOUTO LS. 2010. Seleção de clones de batata com resistência múltipla à pinta preta e aos vírus X e Y. Ciência Rural 40: 1702-1708.

PEREIRA AS. (org). 2010. Produção de batata no Rio Grande do Sul. Sistema de Produção, 19. Pelotas: Embrapa Clima Temperado. 95p.

PINTO CABP; TEIXEIRA AL; NEDER DG; ARAÚJO RR; SOARES ARO; RIBEIRO GHMR; LEPRE AL. 2010. Potencial de clones elite de batata como novas cultivares para Minas Gerais. Horticultura Brasileira 28: 399-405.

RODRIGUES AFS; PEREIRA AS. 2003. Correlações inter e intragerações e herdabilidade de cor de chips, matéria seca e produção em batata. Pesquisa Agropecuária Brasileira 38: 599-604.

ROSSI F; MELO PCT; AZEVEDO FILHO JA; AMBROSANO EJ; GUIRADO N; SCHAMMASS EA; CAMARGO LF. 2011. Cultivares de batata para sistemas orgânicos de produção. Horticultura Brasileira 29: 372-376.

SILVA GO; CASTRO CM; TERRES LR; ROHR A; SUINAGA FA; PEREIRA AS. 2012. Desempenho agronômico de clones elite de batata. Horticultura Brasileira 30: 557-560.

SILVA GO; PEREIRA AS; SOUZA VQ; CARVALHO FIF; FRITSCHE NETO R. 2007. Correlações entre caracteres de aparência e rendimento e análise de trilha para aparência de batata. Bragantia 66: 381-388.

SILVA GO; SOUZA VQ; PEREIRA AS; CARVALHO FIF; FRITSCHE-NETO R. 2006. Early generation selection for tuber appearance affects potato yield components. Crop Breeding and Applied Biotechnology 6: 73-78.

SIMON GA; PINTO CABP; LAMBERT ES; ANDREU MA. 2009. Seleção de clones de batata resistentes à pinta preta e tolerantes ao calor. Ceres 56: 31-37.

TEIXEIRA AL; SILVA CA; PEIXOUTO LS; LEPRE AL. 2010. Eficiência na emergência e produtividade dos diferentes tipos de batatasemente. Scientia Agraria 11: 215-220. 